\title{
As hiper mulheres kuikuro: apontamentos sobre cinema, corpo e performance
}

Alice Fátima Martins*

Resumo: Neste texto são trazidas à pauta algumas questões situadas no entrecruzamento de campos teórico-conceituais que incluem algumas discussões caras à cultura contemporânea. As relações entre corpo, memória e devir são abordadas a partir dos conceitos de performance, ritual e jogo. As análises são ancoradas no filme Itão kuegü: as hiper mulheres (2011), de Takumã Kuikuro, Carlos Fausto e Leonardo Sette, consideradas as circunstâncias de sua realização e veiculação, a narrativa fílmica e a presença das mulheres, que protagonizam o trabalho.

Palavras-chave: hiper mulheres; povo kuikuro; corpo; performance; cinema.

$\mathrm{N}$ este texto são trazidas à pauta algumas questões situadas no entrecruzamento de campos teórico-conceituais que incluem algumas discussões caras à cultura contemporânea, tendo o corpo como fio condutor. O filme Itão kuegü: as hiper mulheres (2011), de Takumã Kuikuro, Carlos Fausto e Leonardo Sette, ancora as reflexões propostas, consideradas as circunstâncias de sua realização e veiculação, a narrativa fílmica e, sobretudo, a presença das mulheres, que protagonizam o trabalho.

\section{Dos filmes etnográficos}

\section{ao coletivo de cinema da aldeia Ipatse Kuikuro}

O cinema, desde seus primórdios, assumiu parceria com pesquisadores e aventureiros que se lançaram a desbravar o desconhecido, incluídas aí comunidades com modos de organização sociocultural distintos das matrizes de tradição europeia. Também, desde os registros documentais mais antigos de que se tem notícia, ainda em película, de rituais e práticas culturais de comunidades as mais diversas, sabe-se tratarem, no mais das vezes, de situações devidamente encenadas, dirigidas, atuadas, de acordo com as concepções fílmicas e cenográficas do aventureiro-pesquisador-cineasta.

O inventor estadunidense Thomas Alva Edison, por exemplo, é considerado por alguns historiadores como responsável pelo registro das primeiras imagens em movimento de cunho antropológico. Com seu kinetoscópio, realizou, em 1894, os filmes Indian

\footnotetext{
* Doutorado em sociologia (UnB), pós-doutorado no Programa Avançado de Cultura Contemporânea da UFRJ, é professora da Universidade Federal de Goiás, autora de Saudades do futuro: a ficção científica no cinema e o imaginário social sobre o devir, Editora UnB, 2013. <profalice2fm@ gmail.com>
} 
war council e Sioux ghost dance. Freire (2005) reitera que se tratam dos "primeiros vestígios animados dos índios Sioux", mas adverte: "[as cenas] foram gravadas em estúdio" (Freire, 2005: 107). Ou seja, os dois filmes configuram a reconstituição de episódios nos quais os sujeitos observados atuam, representando seus próprios papéis sociais e culturais. Para tanto, "foi construído um cenário reproduzindo, de maneira bastante tosca, o habitat natural dos Sioux", informa o autor (Freire, 2005: 107). Em função das limitações do kinetoscópio para a captação de imagens, que requeriam condições especiais de iluminação, os registros foram feitos em West Orange, no subúrbio de Nova York, numa espécie de estúdio conhecido como Black Maria, para onde os performers da comunidade Sioux foram levados a atuar.

Quase três décadas depois, os recursos técnicos para a produção cinematográfica já haviam resolvido muitas das dificuldades técnicas iniciais. Ao conquistar maior sofisticação, ofereciam mais recursos e possibilidades narrativas. Em 1922, o cineasta Flaherty trouxe a público o filme Nanook of the North (Nanook, o esquimó), geralmente apontado como um dos primeiros filmes do gênero documentário. Neste ponto, é importante frisar que essa categoria tem sido atribuída ao filme pelo mercado cinematográfico e por estudiosos e críticos da área, a despeito de o próprio cineasta não ter classificado seu filme como tal. Ainda e assim, sabe-se que seu trabalho recebeu muitas críticas por ter lançado mão de recursos e artimanhas artificiais, visando fortalecer sua narrativa. Por exemplo, o protagonista efetivamente não se chamava Nanook, mas Allakariallak. Nanook, afinal, parece ser um nome mais palatável ao público frequentador das salas de cinema estadunidenses e europeias. Além disso, faz alusão ao mito segundo o qual esse seria o nome do mestre dos ursos, o grande urso polar. Do mesmo modo, no filme, a mulher apresentada como esposa do protagonista, de fato não o era. Essa escolha teria sido justificada pelo diretor em função da beleza da substituta, de acordo com os padrões estéticos estadunidenses. O iglu que, no filme, acolhe a família, foi construído especialmente para as filmagens, sendo maior que os demais, e aberto lateralmente, de modo a acomodar a equipe de gravação e seus aparatos. Ou seja, um ambiente nem um pouco confortável, tendo em vista não estar, de fato, protegido do vento polar ártico e das temperaturas baixíssimas nas áreas externas à residência.

A inserção de recursos do cinema de ficção é apontada por Morais (2008) como um dos fatores que fortalecem a narrativa, despertando a empatia do público, que é convencido tratar-se, efetivamente, de uma realidade documentada. Nesses termos, a autora argumenta que a aproximação do filme documental com a narrativa ficcional, no caso de Nanook of the North, é decisiva para o seu sucesso: sujeitos sociais levados à condição de atores que performam papéis sociais e culturais próprios, cenas cotidianas cuidadosamente reconstruídas, situações de humor, dramaticidade, ambientação em cenários artificiais. 
No decurso do século XX, o francês Jean Rouch foi alçado à condição de referência para o cinema etnográfico. Sua filmografia, toda registrada em campo, foi orientada pela noção de cinema-verdade, que não supõe a possibilidade de apresentar a verdade no cinema, mas de articular narrativas a partir da verdade do cinema (Collen, 1995). As fronteiras do documentário foram atravessadas frequentemente em seus trabalhos, nos quais se observam procedimentos e influências da ficção, do imaginário, bem como os recursos poéticos da linguagem cinematográfica, a despeito da natureza científica das narrativas. Registro, documento, experimentação são elementos constituidores desse território aberto ao encontro entre sujeitos, agentes de cultura, na articulação de linguagem.

No Brasil, a Comissão Rondon foi responsável pela abertura de frentes para a criação e implementação das políticas indigenistas republicanas, no início do século XX. Integrante da Comissão, coube a Luiz Thomas Reis a produção de importantes registros etnográficos até o final dos anos 1930. Seus filmes fazem parte do acervo iconográfico do Serviço de Proteção aos Índios (SPI), hoje sob a guarda do Museu do Índio. Uma parte importante desse material, além de fartas referências fotográficas, foi reunida no livro Memória do SPI: textos, imagens e documentos sobre o Serviço de Proteção aos Índios (1910-1967), organizado por Carlos Augusto da Rocha Freire (2011).

No decurso do século XX, muitos pesquisadores brasileiros e estrangeiros produziram filmes no formato de registros etnográficos. Outros tantos títulos foram realizados, de natureza ficcional, contando histórias sobre índios. Dois traços podem ser considerados comuns a todas essas produções, das etnográficas às ficcionais. O primeiro está na clara distinção entre os filmes de registro documental, etnográfico, endereçados, sobretudo, a pesquisadores, instituições responsáveis por políticas públicas em diversas frentes, entre outras, e os ficcionais, cujo território preferencial é o mercado do entretenimento - estes, em tese, liberados do compromisso com dados documentais ou referenciais etnográficos. O segundo traço está no fato de que as câmeras foram empunhadas e os filmes dirigidos por não índios.

Na segunda metade da década de 1980, o Brasil testemunhava as mobilizações da abertura política, depois da longa vigência da ditadura militar. As políticas indigenistas também passavam por alguma revisão, sobretudo depois de muitas nações terem sido consideradas exterminadas. Foi nesse contexto que Vincent Carelli, antropólogo e documentarista francês radicado no Brasil, iniciou o Projeto Vídeo nas Aldeias. Inicialmente voltado prioritariamente para a produção de vídeos-denúncia, no final dos anos 1990 o projeto passou a investir em processos de capacitação de grupos indígenas, por meio de oficinas de realização e edição. A expectativa apoiou-se na ideia de que os realizadores indígenas pudessem substituir, gradativamente, a descrição visual pela produção de narrativas propiciadas por recursos da linguagem 
cinematográfica. Essas trilhas levaram, entre outros feitos, à inauguração, em 2007, do Centro de Produção Audiovisual na aldeia Ipatse, Kuikuro, no Alto Xingu, Mato Grosso (Cunha, 2010).

As tecnologias digitais no campo do audiovisual popularizaram o acesso aos apareIhos, bem como facilitaram os processos de edição dos registros. Um número cada vez maior de pessoas tem se interessado pela produção de narrativas próprias, que dialogam com seus cotidianos de modo mais direto, dando visibilidade a pontos de vista que não teriam espaço nas grandes produções. Robert Stam e Ella Shohat (2005) destacam as dinâmicas de apropriação, pelas comunidades que historicamente têm estado à margem dos fluxos hegemônicos da economia e do poder, dos processos e procedimentos com os quais podem contar suas próprias histórias, desde seus pontos de vista. Se, como afirmam os autores, o cinema tem assegurado, majoritariamente, espaço para que sejam contadas as histórias dos vencedores, o que se observa é a abertura da possibilidade para que outras histórias sejam contadas - ainda que permaneçam acessíveis a públicos mais localizados, regionais, sem entrarem nos circuitos mais amplos de distribuição e veiculação.

Assim, se durante muito tempo foram os outros que contaram histórias a respeito dessas comunidades, nas décadas mais recentes, com a facilidade de acesso às tecnologias digitais de imagem e som, inaugurou-se a possibilidade de as próprias comunidades contarem não só as histórias sobre si, mas também reinventarem suas próprias histórias e as maneiras de contá-las, bem como performá-las, a partir de seus próprios referenciais temporais, corporais, relacionais e de ambientação.

Esse parece ser o motivador das lideranças kuikuro, que abrigaram a criação do coletivo de cinema em sua comunidade. Dentre os argumentos apresentados, tem destaque, em seus relatos (Cunha, 2010), a possibilidade de registrar eventos, rituais, cantos, estabelecendo um meio de comunicação mais eficiente e passível de atualização entre as gerações mais velhas e os jovens. O que está em questão, além das narrativas e dos registros propriamente ditos, é a mídia, ou o aparato tecnológico por meio do qual se possa estabelecer, de modo mais eficiente, relações dialógicas intergeracionais. A ideia de tomarem para si o papel de pesquisadores e autores de suas próprias narrativas fílmicas abre inúmeras possibilidades para o desenvolvimento de projetos, no esforço de buscar respostas a inquietações e desafios.

A mídia, entendida como agente por meio do qual as imagens são veiculadas, integra uma triangulação indissociável com o corpo e a imagem. O corpo evocado, nessa tripla relação, é tanto o que performa como o que percebe e se percebe. Corpo e mídia modificam-se continuamente. Nesses termos, é possível "falar de uma história das tecnologias visuais" (Belting, 2006: 33), do mesmo modo como se pode estabelecer a 
correlação com uma história da percepção. Também as imagens não existem de modo autônomo na imaginação, na mente das pessoas. Belting afirma:

Elas [as imagens] não existem por si mesmas, mas, sim, acontecem; elas ocorrem, sejam imagens em movimento (o que se torna tão óbvio), ou não. Elas acontecem via transmissão e percepção (Belting, 2006: 33).

Ao discutir os modos como a mídia é incorporada pelos povos indígenas, dentre outras comunidades, Stam e Shohat ressaltam as mudanças pelas quais passaram os filmes etnográficos desde os seus primórdios, até as últimas décadas, quando tem prevalecido, nos discursos fílmicos, a disposição para se despirem de atitudes residuais colonialistas, com abertura a formas dialogais de produção. Em lugar de narrar o outro, forjando neutralidade na apresentação de realidades supostamente objetivas, esses filmes passaram a representar exercícios de alteridade. Destacam, os autores, que

o objetivo, raramente reconhecido, passa a ser o de garantir a efetiva participação do "outro" em todas as etapas da produção, inclusive na produção teórica (Stam \& Shohat, 2005: 413).

Gradativamente, essas comunidades passam a produzir narrativas de si, algumas um pouco mais, outras um pouco menos dependentes de alguma forma de mediação. Em muitos casos, conquistam autonomia nesse processo em que, ainda segundo Stam e Shohat, se observa a coincidência entre quem sejam os realizadores e quem sejam os espectadores: as próprias comunidades e adjacências, ampliado o raio de alcance a algumas instituições relacionadas direta ou indiretamente à temática, e não muito mais do que isso. Esse movimento é portador de fatores que, eventualmente, apresentarão, aos cineastas e videastas indígenas, um dilema assim formulado pelos autores:

Por um lado, utilizam-se das novas tecnologias para a sua afirmação cultural e, por outro, disseminam uma tecnologia que poderá, em última instância, apenas estimular a sua própria desintegração (Stam \& Shohat, 2005: 414).

Problematização semelhante é proposta por Tatiana Bacal (2009) ao questionar como se cria uma cultura, tendo como ponto de partida para a formulação de suas reflexões o Projeto Vídeo nas Aldeias, e a produção fílmica de cineastas indígenas e seus coletivos. Ao intitular seu texto com a pergunta "como criar uma cultura?", dentre outras referências a autora registra as posições de Isaac Pinhanta, autorreferido como professor e realizador ashaninka. Ele saiu da posição inicial contrária às tecnologias de vídeo, passando ao reconhecimento do seu potencial para propiciar discussões sobre as culturas das comunidades indígenas, bem como para auxiliar 
na organização da educação e refletir sobre a vida em comunidade. Reconhece, assim, no vídeo, "um instrumento para defender a cultura" (Bacal, 2009: 141, grifos da autora). Assim, a escrita e a câmera são vistos como instrumentos para a defesa da cultura, mas também para a sua invenção, de acordo com as necessidades da comunidade.

Bacal problematiza alguns pontos dos argumentos de Isaac Pinhanta, principalmente aqueles relativos à ideia de defesa e de invenção da cultura. Se, por um lado,

ao se tornarem autores através da linguagem cinematográfica, os diretores indígenas detêm mais armas para inventar a sua cultura para um grupo cada vez maior de interlocutores (indígenas ou brancos) [por outro lado, quanto mais reflexiva] se torna a sua concepção de cultura frente aos antropólogos e outros "brancos", quanto mais autoria ganha o "nativo", mais ele perde as qualidades que o identificam enquanto "nativo" (Bacal, 2009: 152).

É em espaços intersticiais constituídos a partir de paradoxos dessa natureza que filmes como Itão kuegü: as hiper mulheres são articulados, por meio dos quais seus autores e performers se fazem visíveis, para si e para os outros - os outros que não eles.

Ora, é exatamente nesse entrelugar que a invenção da cultura (em quaisquer comunidades, afinal) se processa, borrando noções de "nativos ideais", de referenciais identitários fixos, afetando o próprio sentido de cultura. O filme Itão kuegü: as hiper mulheres é um dos desdobramentos do Projeto Vídeo nas Aldeias, na instalação do Coletivo de Cinema Kuikuro, no Parque do Xingu, e resulta da negociação entre cineasta indígena, cineasta não indígena e antropólogo. Resulta também da negociação entre registro etnográfico e imaginário, este pensado nos termos propostos por Castoriadis:

O imaginário de que falo não é imagem de. É criação incessante e essencialmente indeterminada (social-histórica e psíquica) de figuras/ formas/imagens, a partir das quais somente é possível falar-se de "alguma coisa". Aquilo que denominamos "realidade" e "racionalidade" são seus produtos (Castoriadis, 1982: 13).

Nesses termos, a polifonia e o impulso para a criação incessante de figuras/formas/ imagens reverberam concepção e produção do filme, contaminando toda a narrativa, frame a frame. 


\section{Itão kuegü: \\ hiper mulheres no entrecruzamento \\ de narrativas e pontos de vista}

Itão kuegü: as hiper mulheres (2011) resulta dos agenciamentos entre três diretores com formações distintas: o cineasta não índio Leonardo Sette, o antropólogo Carlos Fausto e o cineasta Takumã Kuikuro, integrante do Projeto Vídeo nas Aldeias, estudante na Escola de Cinema Darcy Ribeiro, no Rio de Janeiro, transeunte de fronteiras e da possibilidade de se contar histórias por meio das narrativas fílmicas desde pontos de vista diversos.

Nesse trabalho, o marco de partida é um exercício de negociação, em que a distinção entre os papéis de quem filma e é filmado é enfraquecida, na direção de se realizar um filme que, a despeito de transpirar um caráter etnográfico, observa uma estrutura narrativa com todos os elementos típicos de uma história ficcional, contada com imagens em movimento sonorizadas.

A figura do outro, presente nos filmes etnográficos, desfaz-se, perdendo a centralidade na narrativa, na experiência partilhada não só entre os diretores, mas com toda a comunidade que performa em seu próprio cotidiano. Há uma história a ser vivida e a ser contada, e há os sujeitos que a performam, tomando parte da tessitura construída ponto a ponto, cena a cena.

As mulheres são protagonistas, porque hiper mulheres, como o título antecipa. Kuegü, da língua falada pelo povo kuikuro, foi traduzido como hiper, ocupando o lugar de superlativo, e itão corresponde a mulheres. Como o filme conta a preparação e a realização do Jamurikumalu, ritual feminino do Alto Xingu, no Mato Grosso, o título realça a centralidade das mulheres no ritual e no filme, e sua força que se estende desde a situação extraordinária da festa ao cotidiano da comunidade.

Estudos sobre o evento precederam a produção do filme, formando a base para a formulação do argumento central, em torno do qual transcorre o enredo. Nele, o tio pede ao sobrinho que realize o ritual, pois ele teme a proximidade da morte de sua mulher, já velha, a única que conhece todos os cantos da festa. A possível morte sem a realização do ritual implicaria no esquecimento - e perda - de cantos que ela ainda não teve tempo e condições de ensinar para sua sucessora. Kanu, mulher adulta, mais jovem, que tem o conhecimento necessário para realizar o ritual, está gravemente enferma. Enquanto as expectativas se estabelecem em tensão, o cotidiano da comunidade vai se desenhando, e a narrativa se desenvolve.

O tempo gasto para a pesquisa, bem como a duração das gravações, envolveu período mais extenso do que o tempo diegético sugere. Além disso, muitas sequências foram 
reorganizadas de modo a dar mais clareza e força à história, não observando a ordem cronológica das gravações. No entanto, durante o seminário "Pensamento indígena: educação, arte e comunicação", realizado na Faculdade de Artes Visuais da Universidade Federal de Goiás, em julho de 2013, Takumã enfatizou que "tudo no filme é verdade, aconteceu mesmo". Um dos exemplos mais contundentes está no fato de Kanu ter caído gravemente doente, de fato, o que gerou preocupação entre os familiares, e implicou o risco efetivo de o ritual não ser realizado. O evento acabou potencializando a dramaticidade do filme. Em sintonia com Takumã, Carlos Fausto reitera que

nem tudo é verdade no filme, mas tudo é verdadeiro. [E acrescenta:] A câmera estar, permanentemente, na mão deles permite resultados impossíveis para quem não seja do Xingu (Dahen, 2013).

Integrante do grupo de diretores, o antropólogo Carlos Fausto define o trabalho como "um filme sobre música, memória e a transmissão do conhecimento, que passa pelo afeto das relações pessoais" (Dahen, 2013). Trata-se, enfim, de uma história contada por sujeitos performativos, atuando em seu próprio contexto, contando de si, tecendo relações entre passado, presente e futuro, dando-se a ver a outrem. A memória pulsa nas fibras corporais, o exercício de aprendizagem das músicas é indissociável do gesto, da dança, dos afazeres cotidianos. Os corpos transfiguram-se no decorrer dos preparativos para o ritual, ganhando força, chegando à plenitude durante a festa: a plenitude do ritual e das aprendizagens.

Ao longo dos 80 minutos de projeção, a história contada, que se inicia articulando fragmentos do cotidiano, vai ganhando densidade, consistência, dramaticidade, até chegar às cenas grandiosas registradas durante a festa. E se encaminha para a conclusão numa sequência intimista, que acena para o futuro, no vínculo estabelecido entre a mulher adulta, Kanu, que cantarola uma melodia com voz suave e a jovem adolescente atenta que a repete, no delicado ritual de aprendizagem. O ritmo impresso à narrativa mantém a atenção da audiência em sua temporalidade interna.

O filme alinha-se, em muitos aspectos, ao pensamento de Jean Rouche (Collen, 1995), segundo o qual é tênue e porosa a fronteira entre documentário e ficção, e incessante o trânsito entre o que se suponha como o real e o imaginário. Mas não é apenas na concepção da narrativa que há pontos de aproximação: chama a atenção o domínio no uso dos equipamentos. Ao modo de Rouche, os operadores de câmera indígenas dispensam os tripés, e mesmo monopés, na captura de imagens. Em entrevista a Jean-Paul Collen, Rouche relata que trabalhou mais que cinco décadas sem usar tripé. Embora, inicialmente, tivesse feito uso desse equipamento, o tripé o forçava a um ponto de vista único, o que lhe parecia pouco confortável, embora reconhecesse que os resultados visuais tivessem qualidade. O etnógrafo declara preferir estar mais 
próximo às pessoas, e questiona se a adoção desse ponto de vista atrelado ao tripé não evidenciaria também uma escolha pelo distanciamento, um modo de o cineasta não tomar partido.

O equipamento na mão dos cineastas indígenas é operado com precisão no enquadramento, tem firmeza na sustentação mesmo em condições adversas, não treme ou oscila, mesmo dentro da mata, nas correrias, na água, ou entre as centenas de mulheres que avançam dançando e cantando, imbuídas da determinação de não se deixar perturbar por ninguém, mesmo seus pares a realizarem registros fílmicos, em comum acordo. A câmera, integrada ao corpo, acompanha os movimentos, se encaminha com cuidado nos espaços mais íntimos, registra delicadezas, brinca e se diverte com a comunidade. Desse modo, as imagens capturadas portam afetos, memórias, e desejos com os quais contaminam a audiência, tanto indígena quanto não indígena.

Se os diretores não índios têm, por herança, a familiaridade com as narrativas fílmicas, traduzida em repertórios mais amplos, bem como acesso e maior trânsito entre as tecnologias da imagem e do som e seus recursos, os cineastas indígenas têm acesso a ambientes, eventos, situações que outros não teriam. Além disso, a intimidade com os ambientes e os laços com a comunidade conformam um olhar mais atento a certas informações ou a certos detalhes que passariam despercebidos a estrangeiros. Esses traços são observáveis em Itão kuegü: as hiper mulheres, e também são destacados por Takumã Kuikuro, cuja condição de homem casado com uma das mulheres participantes do ritual, e do filme, foi fundamental para que pudesse presenciar certos momentos e estar em certos lugares que, em outra circunstância, não Ihe seria permitido.

Sua esposa também teria contribuído no processo de convencimento das mulheres para a realização do filme. Inicialmente, as protagonistas da festa resistiam à proposta de serem filmadas. No entanto, no decurso dos trabalhos, animaram-se com os resultados. Incorporaram, assim, a ideia de que, filmadas, não morreriam mais. Ao contrário, sobreviveriam "o tempo todo" (Dahen, 2013). Nesse sentido, o princípio de valorização do patrimônio cultural imaterial está na base, também, da realização do filme, que contou com apoio do Instituto do Patrimônio Histórico e Artístico Nacional (Iphan), visando à montagem de um acervo dos cantos das mulheres Kuikuro. Além do filme propriamente dito, resultou desse trabalho o registro com mais de 130 horas de músicas gravadas, sem repetição de melodias.

Apropriar-se de recursos tecnológicos, modos de gestão e recursos narrativos não indígenas, sem deixar de serem índios: as lideranças kuikuro não têm se omitido em relação a esse desafio, ao contrário. O acolhimento, no seio da comunidade, do Projeto Vídeo nas Aldeias é um indicador da abertura a essas possibilidades, a despeito 
de todas as tensões, questões e contradições de que sejam portadoras. As ocas com equipamentos conectados à rede mundial de computadores, aparelhos de televisão com antenas parabólicas, entre outros aparatos, incorporam-se ao cotidiano dessa comunidade que se mostra receptiva às influências externas e, ao mesmo tempo, se esforça para não se perder de seus próprios referenciais. O equilíbrio é sempre muito frágil. As dinâmicas por meio das quais esses movimentos se dão, contudo, nem sempre são livres de conflitos, requerendo frequentes negociações.

Se a comunidade kuikuro, como no mais, toda comunidade, nos termos propostos por Castoriadis (1982), experimenta a tensão entre, de um lado, as forças que tendem à conservação dos modos de organização e das visões de mundo, suas tradições, e, de outro, o impulso para as mudanças, o vir-a-ser, os três diretores do filme foram hábeis no propósito de trazer essa tensão para a narrativa, assegurando a vibração dos acordes nas várias sequências e tomadas. Talvez um dos momentos indicadores dessa marca seja mais explícito na abordagem da doença de Kanu: os rituais xamânicos são aliados à terapêutica não indígena, que se faz representar, naquele contexto, pelos funcionários da Fundação Nacional do Índio (Funai), atuantes no Parque.

Ou seja, Itão kuegü: as hiper mulheres pode ser pensado como produção cultural, fílmica, gestada e gerida por pontos de vista diversos, cujos agenciamentos buscam alcançar um ponto de equilíbrio que passeia na história contada. Longe de configurar um "filme sobre índios", oferece uma estrutura dramática que extrapola, em muito, o registro etnográfico, documental, a despeito de também ser portador dessa potencialidade.

\section{Corpos que se dão a ver, se veem e são vistos}

Daehn (2013), na crítica sobre Itão kuegü: as hiper mulheres, afirma tratar-se de um filme que põe em evidência os corpos de seus personagens, sobretudo, o corpo feminino. Mais que isso, reconhece nele um filme sobre esses sujeitos-corpos, em seus cotidianos, e sua transfiguração em direção ao ritual. Nesse processo, memória e experiência confundem-se, e a cosmologia do grupo é encarnada em sua presença física. Isso explica, por exemplo, que a aprendizagem dos cantos esteja atrelada à própria experiência corporal, e a memorização envolva o sujeito em sua inteireza e presença: nas atividades do dia a dia, nas pausas, nos sonhos. Em lugar de decorar a melodia, numa atividade basicamente mental, buscam-se maneiras de incorporá-la, ou seja, propiciar que o corpo todo se impregne dela, a tal ponto que, ao acordar de madrugada, o sujeito aprendente se surpreenda pensando na melodia. Desse modo, as palavras tornam-se experiência em ato. Assim também, os cantos e o próprio ritual existem como ação, fazendo sentido na medida em que sejam, continuamente, rememorados, reinventados, atualizados. 
No decurso do filme, diante das câmeras, e dos olhos da audiência, os corpos femininos performam. Gradualmente, transformam-se, desde seus cotidianos, da dimensão ordinária dos dias, ganhando força e exuberância na medida em que se preparam para o ritual, chegando ao ápice da festa na plenitude de sua transfiguração.

Ao longo da narrativa, os corpos encontram-se em condições e circunstâncias diversas: desde a doença, a constatação da velhice e a proximidade da morte, passando pelo erogênico e o lúdico, o humor e o deboche, até os complexos processos de aprendizagem e preparação para os cantos e as danças, quando pinturas e adornos integram elementos que ressaltam as condições extraordinárias da experiência. Fragilidade e força, sensualidade e repouso, juventude e velhice dialogam na trama do viver compartilhado e negociado por essas mulheres, em comunidade.

Mas o que a audiência testemunha, vendo o filme, não é o cotidiano dessas mulheres, ou sua participação no ritual. O testemunho é de uma história contada, no filme, por pessoas que se dão a ver, em experiência-ato corporal. Os participantes (que não são atores) atuam, assumindo seus próprios papéis, diante dos aparatos que capturam suas imagens, registrando suas (atu)ações, de modo que possam ser repetidas incontáveis vezes.

As pessoas, que se dão a ver, também veem, e são vistas por outrem. Nessas relações, modificam o modo como percebem a si mesmas, bem como suas próprias atuações. Modificam-se, porque se reinventam a partir da imagem na qual se podem ver. 0 corpo que atua, que lembra, que reconta, que aprende, que recria, em processo incorpora às suas experiências elementos exógenos: a câmera, os equipamentos a ela atrelados, e as narrativas que se podem produzir com essas ferramentas. As histórias, que, quando recontadas oralmente, são transformadas no decurso do tempo, quando articuladas em suporte tecnológico audiovisual passam por uma espécie de cristalização: são sempre as mesmas histórias, preservadas. Os corpos, cuja imagem, gesto, ritmo, sonoridade são capturados pelos aparatos, não envelhecem mais, não se modificam. Do mesmo modo, não se reinventam: repetem a narrativa, fixando informações a serem apropriadas pelos públicos, quaisquer que sejam, em diferentes tempos e lugares.

Essa talvez seja uma maneira de não morrer e, ao mesmo tempo, outra maneira de morrer - afinal a repetição sem transformação caminha em via contrária à da vida. A utilização do audiovisual como aliado na preservação da memória apresenta uma face ambígua. Ao mesmo tempo em que registra, informa, fortalece, oferecendo também outras vias de reinvenção da cultura, opera de modo a tornar fixas informações, fazeres e saberes que, por sua natureza intrínseca, são dinâmicos, em contínua reconfiguração. 
No caso do Jamurikumalu, há 30 anos não era realizado antes da festa que move o argumento central do filme. Quantos elementos se terão transformado desde então? Quanto tempo transcorrerá até a realização do próximo ritual? Quantas narrativas se entrecruzarão nesse processo? Kanu participará da próxima festa? Estará também envelhecida? São perguntas que a vida, em toda sua complexidade e (re)cortes, tratará de responder, em histórias que transcorrem fora dos campos enquadrados por quaisquer aparatos tecnológicos de imagem e som, ainda que com eles dialoguem, e possam ganhar versões para serem ritualizadas e recontadas.

A ritualização de sons e gestos configura a performance, definida por Schechner (2012: 49) como "comportamento ritualizado condicionado/permeado pelo jogo". Rituais são formas por meio das quais as pessoas lembram. Ou seja, pode-se afirmar que são memórias em ação. Mais que isso, por meio dos rituais, as pessoas lidam com transições difíceis.

Entre outras coisas, a festa do Jamurikumalu foi convocada pelo esposo cuja mulher, anciã, pressentia a proximidade da morte, e temia o esquecimento, pela comunidade, dos cantos de que só ela tinha conhecimento. Quando começaram a chegar os convidados para o ritual, começaram também as rodas de conversa, em socialização. Numa das casas, uma visitante, com sorriso terno, olhando para alguém fora do enquadramento da câmera, comentou algo como: "Coitada, ela vai morrer...". A câmera então buscou o rosto da interlocutora, revelando a anciã acolhida pela solidariedade das demais mulheres, em sua travessia.

Por serem memórias em ação, os rituais, mais que expressarem ideias ou visões de mundo, as incorporam, sendo eles próprios pensamento em/como ação. Em seu ápice, na fase liminar, os sujeitos têm suas identidades e lugares determinados no mundo social em suspensão. Nesse momento, ocorre a "possibilidade criativa para o ritual, podendo abrir caminho para novas situações, identidades e realidades sociais" (Schechner, 2012: 63).

Ao operarem na relação binária entre a eficácia da ação e o entretenimento, as performances encontram-se nas relações de tensão entre essas duas possibilidades. É nesse entre que os rituais propiciam, ao mesmo tempo, estabilidade e mudança nas dinâmicas sociais, desde as instâncias individuais ao âmbito do coletivo.

Os rituais eles próprios modificam-se de acordo com as circunstâncias sociais. A introdução de novas tecnologias, por exemplo, resulta em mudanças no modo como os rituais se organizam. Isso pode ser observado nos mais diversos contextos, desde os meios urbanos hiperpovoados a comunidades como a aldeia Ipatse Kuikuro, onde vivem as hiper mulheres que tomam parte do filme. Desse modo, os aparatos 
tecnológicos não repercutem em transformações apenas em aldeias do Parque do Xingu, mas interferem nos rituais da vida contemporânea nos mais diversos pontos geográficos mapeáveis.

Por outro lado, rituais também podem ser (re)inventandos. Recorrentemente, instituições trabalham para fazer com que rituais relativamente novos pareçam antigos e estáveis, o que contribui para a estabilidade social de acordo com este ou aquele projeto ou status quo. Os corpos em performance, ritualizados, vibram na tensão estabelecida entre o novo e o velho, entre as forças que tendem à conservação e as forças que reivindicam inovação. Nessa tensão, são os próprios rituais que engendram abertura de espaço e tempo para o novo, a antiestrutura, onde opera a performance.

\section{Performance, ritual e jogo}

As noções de ritual e de jogo entrecruzam-se na atuação do performer. Os rituais são memória em ação: corpo-memória-ação. Mais que disso, os rituais cumprem o papel de propiciar às pessoas travessias de momentos difíceis, situações que transbordam as normas e normalidades da vida cotidiana, ou as aprendizagens construídas previamente. Por essa razão, durante os rituais e jogos, as pessoas envolvidas se transformam, transitória ou permanentemente. Ao mesmo tempo, tais eventos oferecem alguma estabilidade, ao proporcionar referenciais que delineiam papéis e ampliam repertórios de estratégias para se lidar com transições, argumentos para negociar condições. É desse modo que os rituais "ajudam as pessoas a realizarem mudanças em suas vidas" (Schechner, 2012: 83).

A seu turno, os rituais também se modificam de acordo com as circunstâncias sociais, culturais e tecnológicas em que são realizados. Assim, nos rituais, entram em cena as tensões entre o novo e o antigo, as forças que atuam para a conservação e as que operam pela mudança.

Se o ritual tem uma natureza mais sóbria, se observa hierarquias, o jogo traz o elemento lúdico, no qual se podem fazer coisas que não são "para valer". Brinca-se, fazem-se chistes, debocha-se, provocam-se situações as mais diversas, impregnadas de humor. Desse modo, abordam-se temas, deflagram-se ações que na vida ordinária em geral não são tratadas. Em ação, os jogadores extrapolam limites, embora atuem de acordo com as orientações do jogo.

Em linhas gerais, tais características não se restringem a rituais, jogos ou festas exclusivos das chamadas comunidades diferenciadas, circunscritas a populações menores, vivendo em grupos sociais mais ligados a práticas tradicionais. A ritualização faz-se 
presente em toda vida social, em sociedades mais complexas, com os meios urbanos, mesmo quando, muitas vezes, as pessoas acreditam estar agindo espontaneamente.

O Jamurikumalu pode ser pensado como evento entretecido pelo ritual e pelo jogo. A festa, em alguma medida, prepara a comunidade, do mesmo modo que a velha muIher e sua família, para a travessia da morte, além de proporcionar aprendizagem às novas gerações. O medo da perda deflagra toda a mobilização para a festa. A resposta ao medo é o ritual em toda sua potência, a força do encontro das mulheres, seus cantos, sua pujança.

Enquanto preparam-se para a festa, as mulheres "podem" muitas coisas, como fazer piadas sobre os homens, jogar com sua sexualidade, brincar com o erógeno, experimentar a força bruta: "Essas mulheres detonam!", exclama um dos homens, vendo as mulheres lutarem entre si.

Mas o ritual-jogo também se modifica pois, além de festa como travessia, como memória em ação, o Jamurikumalu acontece em situação de excepcionalidade, porquanto todos os passos e etapas correm diante de câmeras que registram cada momento, gesto, expressão, fala, sutileza, força. Assim, o que é dado a ver ao público - indígena e não indígena - não é apenas performance em um complexo ritual entremeado ao jogo, mas uma performance que se dá a ver ao mesmo tempo in loco e por meio do registro audiovisual, agregando os equipamentos e seus operadores em suas dinâmicas. Assim, entre os performers, comparecem novos papéis: os papéis daqueles que tratam de capturar sons e imagens em movimento, para produzir narrativas outras. Aqueles que produzem filmes, agenciando pontos de vista indígenas e não indígenas nas histórias que contam sobre e a partir dos rituais. O que também pode ser entendido como jogo.

O registro audiovisual dos cantos, da festa, de todo o processo de preparação do ritual corrobora - a comunidade entende assim - a memória coletiva, propiciando meios de preservação e compartilhamento de saberes, particularmente dos cantos, que todos temem se percam no desfazimento do esquecimento.

Nesses termos, corpo em ação, jogos, rituais, articulados em performance, aliados aos recursos tecnológicos dos registros audiovisuais e da produção das novas narrativas acenam para a ampliação de possibilidades de preservação da memória. Ao mesmo tempo, abrem horizontes outros de transformação, quando não de reinvenção da própria cultura, em narrativas dinâmicas, com argumentos e enredos em contínuos desdobramentos.

Em festa, executa-se o jogo de tomar parte do ritual e de atuar para a câmera. Mais que viver o ritual, os membros da comunidade convencem a audiência de que vivem o 
ritual, desfazendo qualquer impressão de que possam estar atuando para as câmeras. Ao fazê-lo, produzem registros da experiência na memória do corpo, além dos arquivos digitais produzidos pelos equipamentos audiovisuais.

O corpo mostra-se ao registro audiovisual, ao mesmo tempo em que se engaja inteiramente com a experiência e a memória. Cada performer faz de conta que atua, executando papéis que articulam seus referenciais culturais sementais. Mas parece desconsiderar a câmera, vivendo a festa, não mais que isso. Os corpos em festa dão-se a ver. O que é para ser visto também é para ser vivido e sentido, visceralmente. Essa intensidade transborda na projeção de Itão kuegü: as hiper mulheres.

\section{"Misto de besta e anjo da madrugada dos tempos"...}

Para a divulgação do filme, foram criadas páginas na rede mundial de computadores. Dentre elas, abriu-se uma página no site de relacionamento social Facebook. Imagens dos cartazes foram inseridas, bem como dados técnicos, notícias sobre as salas de exibição e as premiações, além de fotos dos ambientes de filmagem e frames do próprio filme.

A administração do site de relacionamento social censurou as fotos nas quais as muIheres aparecem de frente, mostrando o corpo inteiro. O argumento apoia-se no princípio do bloqueio à pornografia, ou exposição de nus, que possam ofender a moral dos demais usuários ligados àquela rede de relacionamentos. Determinou-se, então, que se colocassem tarjas pretas nas imagens, ocultando os seios e o púbis das mulheres. No embate transcorrido entre a produção do filme e a administração da plataforma digital, as tarjas pretas foram substituídas por círculos vermelhos que encobrem as partes pudendas dos corpos femininos. O fato foi noticiado em alguns jornais de circulação nacional (Gragnani, 2013).

Mais do que a manifestação de uma censura aparentemente conservadora, ou mais que o funcionamento de algum algoritmo aleatório adotado pela administração do site na rede mundial de computadores, este evento, dentre tantas questões a ele entrelaçadas, explicita relações com o corpo, e dá pistas sobre dissenções possíveis decorrentes desses trânsitos entre, ante a figura questionada do outro. Por que os corpos dessas muIheres são censurados, de modo não negociável, enquanto imagens de quantos outros corpos femininos, masculinos e de outros gêneros, nus ou seminus, com apelo erótico ou não, têm assegurado espaço de mercado e de publicação nessa mesma rede? De que informações são portadores tais que justifique sua adjetivação como obscenos?

O verbete obsceno, de origem latina, refere-se ao que é vulgar, indecente, sem pudor, e, por isso mesmo, ofensivo. Mas obsceno também tem o sentido daquilo que está 
fora da cena, que não comparece ao campo visível, e por isso mesmo provoca a imaginação. Nas artes da cena, o que não é mostrado, mas sugerido, ganha potência. A expressão fora da cena também qualifica aquilo que não deve ser trazido à presença da audiência, que deve ser ocultado - eventualmente até mesmo apagado - não só do campo da visão, como também da memória.

O corpo é palco de tabus e atribuições de qualidades obscenas. Baudrillard, no livro Da sedução (1992), observa que, numa história que pudesse ser produzida sobre o corpo, o percurso iria desde o sexo escondido, à emergência da nudez. E acrescenta que, quando o corpo nu emerge, é como corpo de mulher, de modo que a noção de corpo tende a se confundir com o corpo feminino. Em cada tempo, e a cada contexto, o corpo, representado pelo corpo feminino, comparece entrelaçado às referências normativas, morais, econômicas, políticas, dentre outras, nas quais se encontra inserido. Modos de produção no trabalho, entretenimento, rituais, noções de beleza vestem, marcam, inscrevem-se no corpo.

No cenário contemporâneo, em que prevalecem as dinâmicas da sociedade de consumidores, as relações não se dão mais entre sujeitos que consomem e mercadorias a serem consumidas, mas os próprios sujeitos ocupam o lugar do item a ser consumido (Bauman, 2009). O corpo, nesse contexto, é vivido como item de consumo, reificado, coisa que se possui. Por essa razão, o corpo deve ser disciplinado, modificado, reconfigurado ao gosto do freguês. Toda uma complexa malha do mercado está montada para atender às demandas de transformações e transfigurações do corpo, na busca de moldá-lo de acordo com expectativas as mais diversas: desde a busca radical por certos padrões de beleza, à mudança de orientação de gênero, passando por projetos estéticos que se pretendam transgressores.

Esse corpo-item-de-consumo, para Baudrillard (1996), deve ser submetido a conjuntos de procedimentos que o retirem da condição de obscenidade. Por exemplo, é preciso retirar, da visão que dele se tenha, as marcas do tempo, as deformidades. Sobretudo, é necessário ocultar-Ihe os orifícios. Ao analisar imagens de corpos veiculadas em peças publicitárias, o autor nota que há uma espécie de compulsão para revestir os corpos, mesmo quando nus. Como se fosse necessário retocá-los, vitrificá-los, encerá-los, para que se mantenham limpos e abstratos. Cada vez mais conceituais. Quem sabe, assim, se possa conquistar a imortalidade para esse corpo mortal?

Talvez seja esse o elemento visível nos corpos das hiper mulheres no qual reside a suspeição de obscenidade, desde o ponto de vista da rede social na qual suas imagens foram censuradas: são corpos que colocam à mostra as inscrições de suas histórias pessoais e de grupo, sem dissimular a textura da pele, dos cabelos, a forma dos quadris, das pernas. São porosos, irregulares, não se deixam plastificar (tanto no sentido 
de se cobrir por alguma película impermeável, quanto de se submeter a cirurgias plásticas...). Embora estejam cuidadosamente vestidos, adornados e com a pele coberta por desenhos, obscenamente não foram encerados ou vitrificados, tampouco se pretendem imortais. Ao contrário: a proximidade da morte de uma dessas mulheres é que os move para a festa, para o ritual. Ocupam a cena, dando-se a ver.

A visão desses corpos impressiona por sua densidade e presença. Mas, ao mesmo tempo, provoca reações que deflagram a censura - o que revela algum potencial transgressor, ou obsceno, ainda que numa perspectiva desde fora do contexto próprio de sua atuação. De uma ou de outra forma, esses corpos, dada a força de sua atuação, não passam despercebidos. Ao contrário.

Armindo Bião (2011), ao problematizar a presença do corpo em cena, noção cara ao campo da etnocenologia, e todas as tensões que integram a questão, em encruzilhadas ao mesmo tempo respeitadas e temidas, onde, simultaneamente, se encontram o maravilhoso e o perigoso, pondera:

\footnotetext{
Nossa polirritmia corporal brasileira deve vir daí, desse corpo arcaico (misto de besta e anjo da madrugada dos tempos) que persiste, sempre presente, ansiando a cena, como meio de vida ou de sobrevivência. Tudo bem. Mas querer resgatar tradições? Quais? De quando? De antes, durante ou depois de tantas escravidões? E nosso componente ameríndio? Qual? O do guerreiro antropófago? Ou só o do guerreiro, ou só o do antropófago, ou o do (talvez) ecológico? Ou o de nosso antepassado aventureiro, explorador, colonizador e inventor de novas tecnologias de navegação e de construção de teatros da Península Ibérica? Alguma dessas matrizes (étnicas?) é só animal ou só angelical? Não são todas elas humanas? Não seriam todas mistas de deuses e diabos? Não seria melhor talvez não resgatar nada? Mas sim compreender essas nossas matrizes e viver a presença morena (mista, de hoje) do corpo em cena? As encruzilhadas do tempo são também encruzilhadas do espaço, que entram e saem pelos 12 buracos (inclusive o umbigo) de nosso corpo, moreno, morena... (Bião, 2011: 357).
}

Câmera, ação:

sequência final, gravando!

Kanu, a mulher que liderou a realização do Jamurikumalu, está recostada na rede. O corpo, despido da roupa de festa, plenamente recuperado da doença, repousa, suspenso. Mas não está entregue à inação: delicadamente, canta para uma adolescente, sentada a seu lado, que ouve, com suave atenção. A luz é diáfana, o contexto é intimista, afetivo. Então a menina começa a entoar a melodia, com doçura na voz. 
O vir-a-ser desenha-se ali, nas relações entre mulheres de três gerações: a mulher anciã, ausente da cena, mas deflagradora da festa - e, portanto, do filme - que, de alguma forma, se prepara para morrer; a mulher adulta, a quem, por conhecer os cantos rituais, cabe a responsabilidade de entoá-los na festa e ensiná-los; e a menina que, ainda impregnada pela força do ritual recém-realizado, lança-se à experiência de aprender as músicas para, quem sabe, no futuro, ser ela a liderar outra festa. 0 espaço-tempo, em seus enredos-encruzilhadas que entram e saem pelos 12 buracos do corpo (não seriam 13 os buracos nos corpos femininos?), mostra e oculta, de uma só vez, elementos impregnados de devir. Devires...

A voz entoando o cântico, o olhar entre ambas, a entrega física ao momento: estes elementos constituem a densidade da cena, fechando a narrativa fílmica. Elas contam a sua história. Cantam uma para a outra. Mas sabem que a experiência não está circunscrita àquele momento: cantam, também, para o aparato que captura e registra sua atuação e a atmosfera em que estão imersas. Portanto, cantam para o público, ou os públicos nas salas de projeção, nas sessões de cinema a se realizarem em lugares desconhecidos para ambas. Ou na intimidade de domicílios com cujos habitantes não compartilham qualquer relação...

As pessoas desses outros lugares as veem, e ouvem o seu canto, depois de terem acompanhado a narrativa fílmica sobre a festa. Elas, assim como a comunidade da qual tomam parte, não serão as mesmas daquela imagem a se repetir na gravação. Como os demais, se terão transformado, desde o advento do filme. Afinal, que pessoas e quais comunidades permanecem as mesmas no decurso do tempo?

Abstract: In this text, I present some points situated in the crossing between theoretical and conceptual fields that include some relevant discussions on contemporary culture. Relations between body, memory and future are addressed from the concepts of performance, ritual and play. The analyses refer to the movie Itão kuegü: as hiper mulheres (2011), de Takumã Kuikuro, Carlos Fausto and Leonardo Sette, and consider the circumstances in wich it has been made, the filmic narrative and the presence of women, who are the protagonists of the film.

Key words: hyper women; Kuikuro people; body; performance; cinema.

\section{Referências}

ALMEIDA, Milton J. de. Investigação visual a respeito do outro. Disponível em <http:// www.lite.fae.unicamp.br/papet/2002/fe190d/texto10.htm>. Acesso: 20 Jun. 2013.

AS HIPER MULHERES. Documentário, drama. Direção: Takumã Kuikuro, Carlos Fausto e Leonardo Sette. Tecnologia digital. Colorido, estéreo. 80 min. Brasil, 2012. 
BACAL, Tatiana. Como criar uma cultura? Índios, brancos e imagens no Vídeo nas Aldeias. In GONÇALVES, Marco A.; HEAD, Scott. Devires imagéticos: a etnografia, o outro e suas imagens. Rio de Janeiro: 7 Letras, 2009.

BAUDRILLARD, Jean. Da sedução. Campinas: Papirus, 1992.

—. Troca simbólica e a morte. São Paulo: Loyola, 1996.

BAUMAN, Zygmunt. Vida para consumo. Rio de Janeiro: Jorge Zahar, 2008.

BELTING, Hans. Imagem, mídia e corpo: uma nova abordagem à iconologia. Revista de Comunicação, Cultura e Teoria da Mídia, n. 8, Centro Interdisciplinar de Semiótica e Cultura da Mídia (Cisc), São Paulo, Jul. 2006.

BIÃO, Armindo J. de C., A presença do corpo em cena nos estudos da performance e na etnocenologia. Revista Brasileira de Estudos da Presença, v. 1, n. 2, Porto Alegre, Jul./Dez., 2011, p. 346-359.

CASTORIADIS, C. A instituição imaginária da sociedade. Rio de Janeiro: Paz e Terra, 1982.

COLLEN, Jean-Paul. Entrevista: Jean Rouch, 54 anos sem tripé. Cadernos de Antropologia e Imagem, v. 1. Rio de Janeiro, UERJ, 1995.

CUNHA, Leandro B. Cinema de índio: a produção audiovisual kuikuro. 2010. Dissertação (Mestrado) - Programa de Pós-Graduação em Cultura Visual, Universidade Federal de Goiás, Goiânia, 2010.

DAEHN, Ricardo. Crítica: As hiper mulheres. Disponível em <http://www2.correiobraziliense.com.br/44festival/artigo4.htm>. Acesso: 12 Jun. 2013.

GRAGNANI, Juliana. Fotos de índias nuas no Facebook ganham tarja preta após remoção. Folha de S. Paulo. 14 Mar. 2013. Disponível em <http://www1.folha.uol.com.br/ ilustrada/1246362-facebook-cobre-fotos-de-indios-nus-em-perfil-de-filme-brasileiro-com-tarjas-pretas.shtml>. Acesso: 20 Mar. 2013.

FREIRE, Carlos Augusto da Rocha (Org.). Memória do SPI: textos, imagens e documentos sobre o Serviço de Proteção aos Índios (1910-1967). Rio de Janeiro: Museu do Índio-Funai, 2011.

FREIRE, Marcius. Fronteiras imprecisas: o documentário antropológico entre a exploração do exótico e a representação do outro. Revista Famecos, n. 28, Porto Alegre, Dez. 2005.

MORAIS, Tatyanne de. Nanook, o esquimó: discurso documental em consonância com as estratégias ficcionais. Anais do XXXI Congresso Brasileiro de Ciências da Comunicação. Natal: Intercom, 2008. 
NANOOK, o esquimó. Título original: Nanook of the North. Documentário. Direção: Robert Flaherty. Película, preto e branco, silente. 55 min. EUA, 1922. Disponível em <http://www.youtube.com/watch?v=v-dQbuW4kY4>. Acesso: 15 Jul. 2013.

SCHECHNER, Richard. Ritual. In LIGIÉRO, Zeca (Org.). Performance e antropologia de Richard Schechner. Rio de Janeiro: Mauad X, 2012.

—. Jogo. In LIGIÉRO, Zeca (Org.). Performance e antropologia de Richard Schechner. Rio de Janeiro: Mauad X, 2012.

STAM, Robert; SHOHAT, Ella. Teoria do cinema e espectatorialidade na era dos "pós". In RAMOS, Fernão Pessoa. Teoria contemporânea do cinema, v. 1: "Pós-estruturalismo e filosofia analítica". São Paulo: Editora Senac, 2005. 